
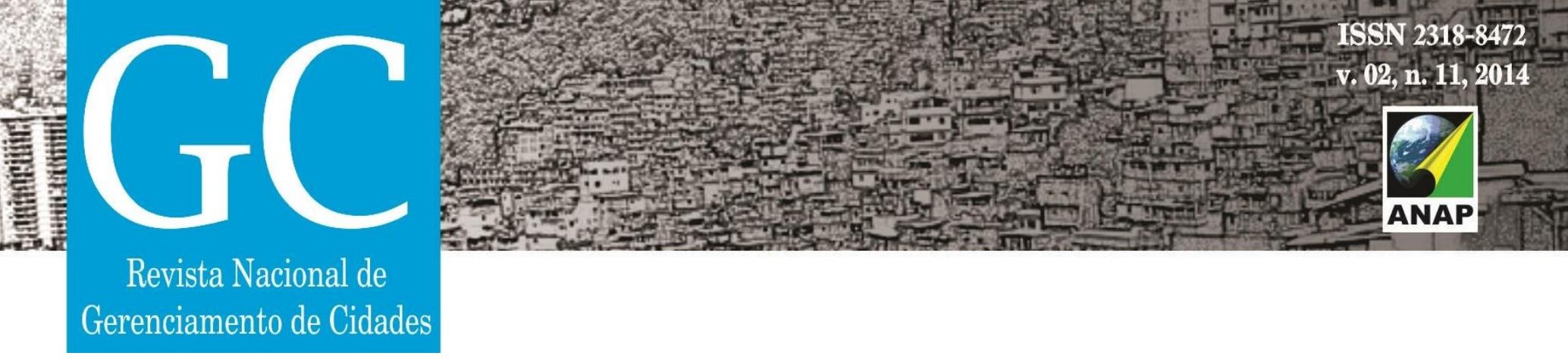

\title{
A IMPORTÂNCIA DA CARACTERIZAÇÃO PARA IDENTIFICAÇÃO DO RESÍDUO PERIGOSO NO RESÍDUO SÓLIDO DOMICILIAR
}

\author{
Mariana Cortijo Costa ${ }^{1}$
}

Eglé Novaes Teixeira ${ }^{2}$

\begin{abstract}
RESUMO
Atualmente, um dos grandes desafios da humanidade é como dispor a enorme quantidade de resíduo sólido gerada diariamente, principalmente nos grandes centros urbanos, pois a geração do resíduo sólido doméstico traz implicações econômicas, ambientais e sociais. Outro problema é o descarte inadequado de resíduo perigoso misturado ao resíduo doméstico. Neste trabalho, buscou-se identificar esse material perigoso no resíduo sólido domestico de Cabreúva-SP. Assim, foram realizadas caracterizações do resíduo gerado no município. Nas caracterizações foram identificadas a composição do resíduo gerado na cidade e a quantidade de resíduo perigoso descartado. Após a caracterização, os resultados foram analisados e avaliados para proposição de medidas que auxiliem na melhora ambiental do município.
\end{abstract}

PALAVRAS-CHAVE: Instrumento de gestão. Gerenciamento de resíduo. Sustentabilidade urbana.

\footnotetext{
${ }^{1}$ Mestranda em Engenharia Civil, Universidade Estadual de Campinas, Faculdade de Engenharia Civil, Arquitetura e Urbanismo, Departamento de Saneamento e Ambiente.

E-mail: mariana.cortijo@yahoo.com.br.

${ }^{2}$ Professora Universitária e Engenheira Civil, Universidade Estadual de Campinas, Faculdade de Engenharia Civil, Arquitetura e Urbanismo, Departamento de Saneamento e Ambiente.

E-mail: egle@fec.unicamp.br
} 


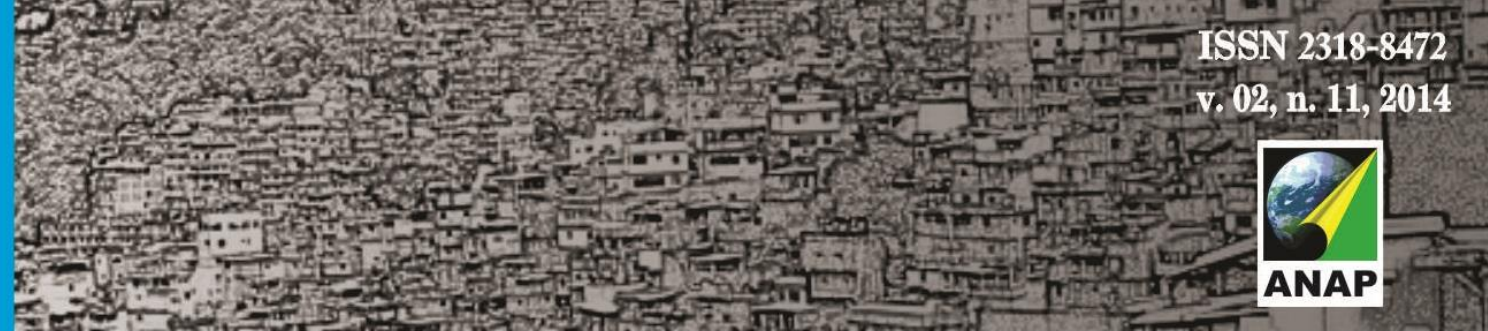

Revista Nacional de Gerenciamento de Cidades

da poluição e da contaminação e o desperdício de energia, fez com que a sociedade e seus representantes, em resposta a estas questões, editassem leis e buscassem tecnologias para evitar, ou ao menos mitigar, tais problemas.

De acordo com a Organização Pan-Americana de Saúde (1999), a maioria dos problemas ambientais é de caráter local e tem repercussão direta na saúde e na qualidade de vida das pessoas. Dentre esses problemas, pode-se destacar a inadequada gestão e gerenciamento de resíduo sólido, em particular o resíduo perigoso.

A falta de planejamento e saneamento adequado na maioria das cidades brasileiras proporciona a diminuição dos recursos naturais e poluição do ambiente, expondo a população a grandes riscos (SIQUEIRA e MORAES, 2009).

Percebe-se ser latente a necessidade de se estudar e tratar destas questões de forma integrada e estratégica, considerando fatores como o aumento da população e o consequente consumo e descarte de diferentes tipos de resíduos e suas implicações sociais e econômicas, buscando alternativas que minimizem seu impacto sobre o meio (PIRANI, 2010).

Com relação ao resíduo perigoso, estudo de caracterização do resíduo sólido domiciliar, realizado no município de Cabreúva, no Estado de São Paulo no período de maio de 2012 a março de 2013, demonstrou que a população local tem o hábito de descartar estes bens pós-consumo, como pilhas, baterias, lâmpadas fluorescentes e fármacos, no resíduo domiciliar.

Pelo fato destes produtos causarem consequências danosas ao meio, podendo contaminar o ar, solo e água, quando descartados inadequadamente, foram editadas normas que regulam seu manejo e disposição, no entanto, verifica-se descumprimento da legislação vigente por parte dos consumidores, fabricantes, importadores, distribuidores, comerciantes e do próprio Poder Público.

Este quadro apresenta um grande desafio, tendo em vista a necessidade de se estruturar um sistema que contribua para a mudança de comportamento, para a prevenção das consequências oriundas da insustentabilidade do modelo de 

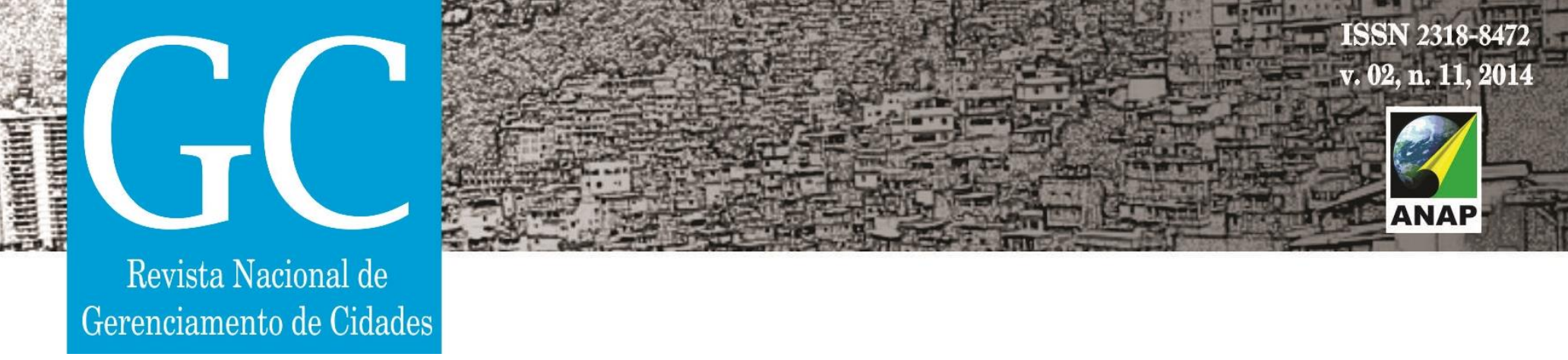

Revista Nacional de

Gerenciamento de Cidades

O gerenciamento do resíduo sólido exige um conhecimento sistemático e aprofundado das características do resíduo, o que é obtido com a caracterização do resíduo já que a caracterização indica a quantidade e a qualidade (características) do resíduo descartado, além de fornecer subsídio e informações para uma correta avaliação das potencialidades econômicas, planejamento e avaliação dos sistemas de coleta, tratamento e disposição final.

Existem vários métodos de caracterização do resíduo sólido, assim, na escolha do método deve-se considerar o objetivo da caracterização, levando-se em conta a realidade do local e definindo-se as regiões onde será realizada, o número de amostras, sua distribuição temporal, os recursos humanos, financeiros e materiais disponíveis (IPT/CEMPRE, 2000).

De acordo com Nagle (2004) as metodologias de caracterização evoluem visando ao conhecimento aprofundado do resíduo, tendo em vista as alternativas de valorização e programas implantados ou a serem implantados, como por exemplo a coleta seletiva ou sistema de logística reversa.

\section{LOGÍSTICA REVERSA}

A PNRS, instituída pela Lei ํo 12.305/10, representa avanço nas discussões referente à questão do resíduo sólido e representa um importante instrumento legal ao ratificar os princípios do poluidor-pagador, da prevenção, da precaução e da responsabilidade compartilhada pelo ciclo de vida do produto.

Pode-se dizer que esta lei traz grandes contribuições para a sociedade na temática de resíduo, pois são instituídas ferramentas como, os planos de gerenciamento de resíduos, a coleta seletiva com a participação prioritária de cooperativas e associações de catadores de material reciclável e os sistemas de logística reversa pautados nos princípios do desenvolvimento sustentável, já bastante discutidos em diversos encontros internacionais e recepcionado pelas leis brasileiras.

Para Monteiro (2013), é a partir dos anos 90 que a logística reversa tem ampliado os seus objetivos, que passam a ser não somente o retorno de bens para 


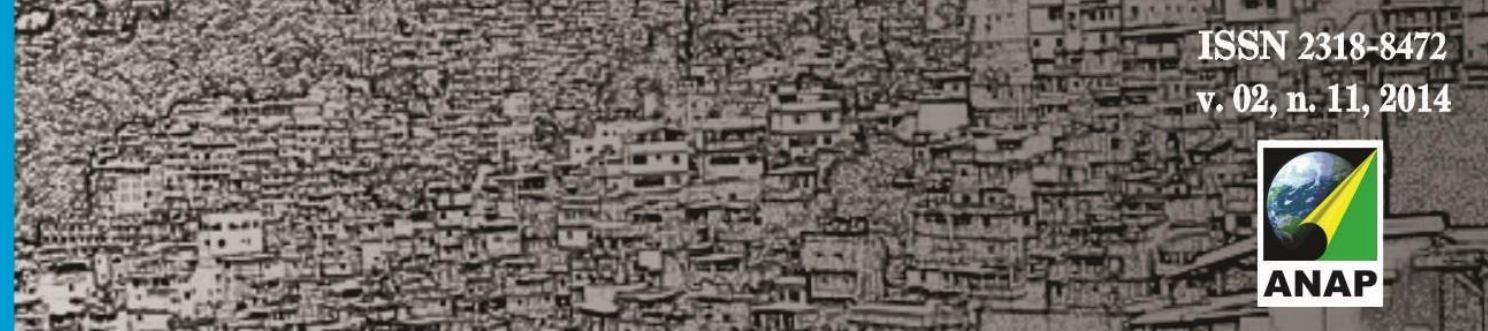

Revista Nacional de Gerenciamento de Cidades

reciclagem, mas também a redução do ciclo de vida dos produtos, diminuição de custos e mudança da imagem coorporativa, que agregou o viés ecológico.

Assim, na logística reversa cuida-se dos fluxos de material que se iniciam nos pontos de consumo dos produtos e terminam nos pontos de origem, com o objetivo de recapturar valores ou disposição final (MONTEIRO, 2013).

De acordo com a PNRS (BRASIL, 2010), logística reversa consiste em um instrumento de desenvolvimento econômico e social, caracterizado pelo conjunto de ações, procedimentos e meios destinados a viabilizar a coleta e a redistribuição do resíduo sólido ao setor empresarial, para reaproveitamento, em seu ciclo ou em outros ciclos produtivos, ou outra destinação final ambientalmente adequada.

Com esta Lei impõe-se aos fabricantes, importadores, distribuidores e comerciantes a elaboração, estruturação e implantação da logística reversa, ou seja, - retorno de seus produtos após serem utilizados pelos consumidores, independentemente do serviço público de limpeza urbana.

O sistema de logística reversa é pautado, dentre outros, nos conceitos dos princípios do poluidor-pagador e da responsabilidade compartilhada pelo ciclo de vida do produto.

No princípio do poluidor-pagador busca-se evitar a ocorrência de danos ambientais, ou seja, impõe-se ao poluidor o dever de arcar com as despesas de prevenção de danos ao ambiente que a sua atividade possa ocasionar. Neste primeiro aspecto do princípio manifesta-se caráter preventivo; e, ocorrido o dano, busca a sua reparação, assumindo-se, portanto, um caráter repressivo, e desta forma o poluidor será responsável pelo dano provocado ao ambiente em razão da atividade desempenhada.

Nesse sentido, no princípio do poluidor-pagador tem-se o objetivo de eliminar, do processo produtivo, suas externalidades negativas.

Assim, para que a coletividade não tenha que arcar com os prejuízos ambientais decorrentes de atividades produtivas e econômicas, Aragão (1997) já mencionava que as externalidades ambientais negativas devem ser internalizadas no 


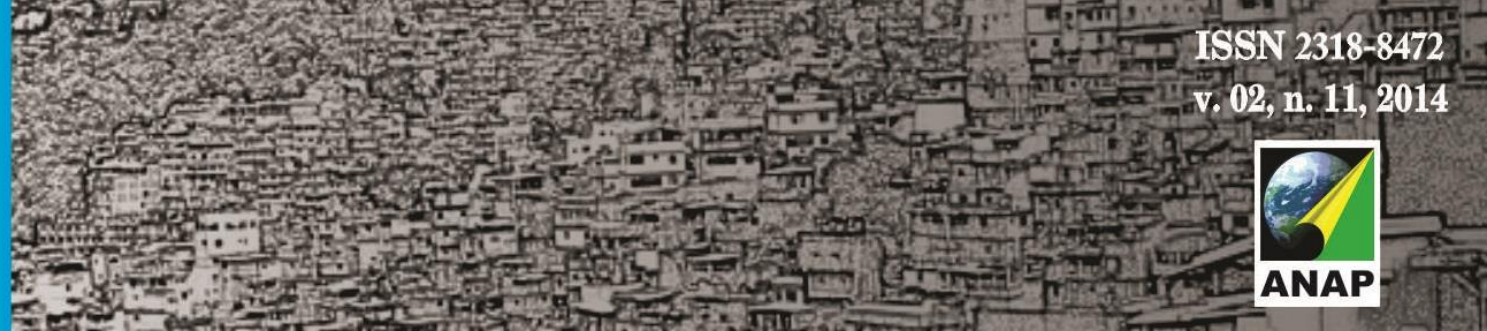

Revista Nacional de Gerenciamento de Cidades

de logística reversa, cabe ao consumidor a responsabilidade ambiental pelo descarte adequado de produtos industriais pós consumo, como é o caso das pilhas, baterias, lâmpadas fluorescentes e medicamentos, sendo inadmissível, portanto, descartá-los juntamente com seu resíduo domiciliar.

\section{METODOLOGIA}

O município de Cabreúva foi selecionado para esta pesquisa em decorrência de alguns fatores. O primeiro critério avaliado para escolha do município foi sua posição geográfica no centro de um triângulo formado pelas rodovias da Grande São Paulo, Região Metropolitana de Campinas, Jundiaí e Sorocaba que representam importantes polos industriais e econômicos para esta região.

Aspecto importante na escolha do município foi a colaboração e aceite da Administração Pública para a realização da pesquisa, propiciando condições favoráveis para a coleta e caracterização do resíduo sólido.

O município de Cabreúva está localizado na região sudeste do Estado de São Paulo. Com cerca de 26.100 ha, toda a extensão do município é considerada Área de Proteção Ambiental e sua população estimada, pelo IBGE para o ano de 2013, é de 45.112 habitantes (IBGE, 2013).

Para a caracterização do resíduo sólido domiciliar do município de Cabreúva, para identificação do resíduo perigoso, levou-se em consideração alguns fatores, tais como a escolha de três bairros de classes sociais distintas; o número de residências, das quais seriam coletadas o resíduo; período e frequência do estudo gravimétrico; e, roteiro da coleta das amostras para pesquisa. Estes fatores foram combinados com o cenário já existente na cidade, ou seja, horário e frequência da coleta regular, particularidades da coleta, distância entre os bairros e frota utilizada.

Adotou-se o número de vinte residências em cada um dos três bairros por dia de coleta para caracterização, número considerado viável tendo em vista à necessidade de se realizar a coleta, a pesagem do resíduo bruto, a triagem do material e o descarte no mesmo dia. 

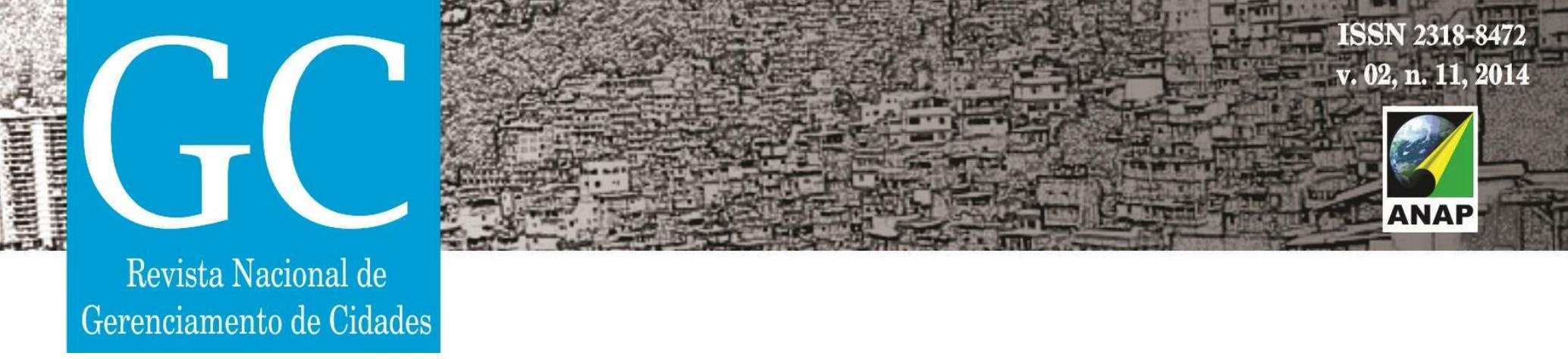

Com relação ao valor identificado para o resíduo denominado PerigososOutros, deve-se esclarecer que a maioria das famílias das residências sorteadas para a caracterização nos bairros de classe alta e média tinha animais domésticos, principalmente cachorros de médio e grande porte, e suas fezes foram classificadas nesta categoria.

Da massa total do resíduo perigoso coletado e caracterizado, o químico representou uma porcentagem de $2 \%$, tendo sido classificados nesta categoria: medicamentos, lâmpadas, baterias e pilhas descartadas (Figura 6).

Figura 6: Porcentagem de Resíduo Químico Encontrada no Resíduo Domiciliar das Classes Alta, Média e Baixa

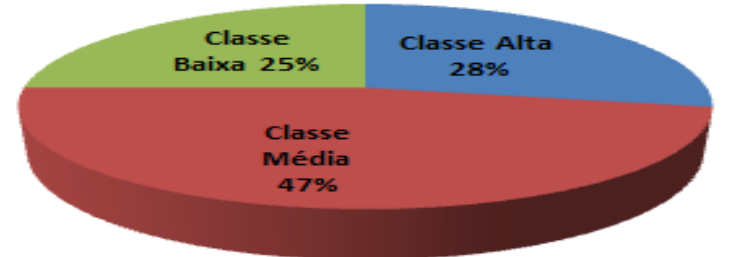

Desta porcentagem, a classe que apresentou maior descarte destes objetos foi a classe média. Durante a caracterização do resíduo desta classe foi identificado uma quantidade significativa de medicamentos, adultos e pediátricos (Figura 7).

\section{Figura 7: Medicamentos Encontrados no Resíduo Domiciliar Coletado no Bairro de Classe Média}
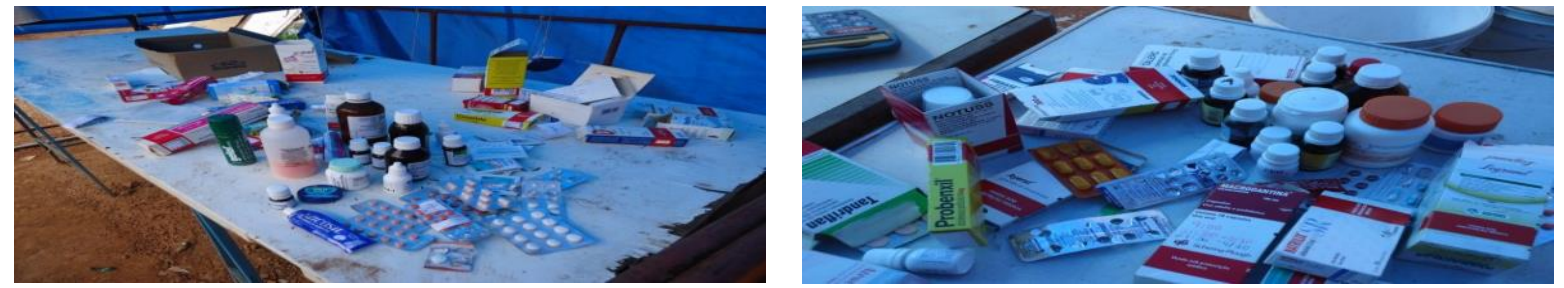

Fonte: Arquivo pessoal, 2012, 2013

A identificação de resíduo químico misturados ao resíduo domiciliar demonstra que a população não sabe como ou não tem onde descartar este material, 


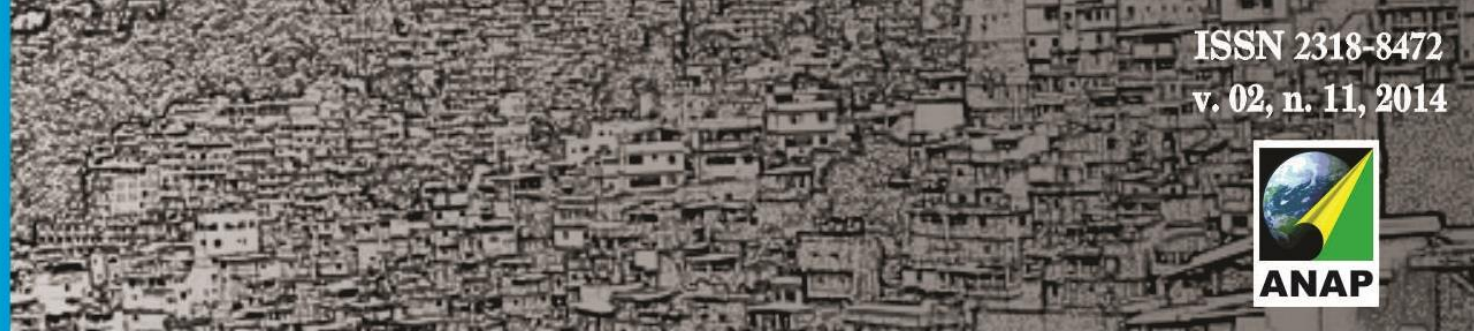

Revista Nacional de Gerenciamento de Cidades

ou ainda, não se preocupam em descartar corretamente esse resíduo, que é comum em qualquer residência de qualquer classe.

Durante o período de caracterização do resíduo sólido domiciliar do município foi possível identificar o descarte de $53,4 \mathrm{~kg}$ quantidade de resíduo perigoso, entre eles lâmpadas, pilhas, baterias, eletrônicos e fármacos.

Percebe-se, assim, a necessidade de informar a população de Cabreúva quanto ao descarte correto deste resíduo, alertando-os dos problemas ambientais e de saúde ocasionado por esse material, mas, ao mesmo tempo, deve ser proporcionado ao consumidor local apropriado para descartar seu bem pós-consumo.

Na PNRS (BRASIL, 2010), que entre outros contempla o princípio do poluidorpagador e da responsabilidade compartilhada pelo ciclo de vida do produto e a exigência da elaboração e implementação do sistema de logística reversa aos fabricantes, importadores, distribuidores e comerciantes de alguns tipos de produtos, entre eles aqueles encontrados durante a caracterização misturados ao resíduo sólido domiciliar, recomenda-se à Administração Pública cadastrar esses sujeitos mencionados na Lei e exigir o cumprimento do artigo 33 da Lei.

Desta forma, a Administração Pública poderá estruturar e implantar EcoPontos em locais estratégicos para que a população descarte alguns desses materiais, como pilhas, baterias e lâmpadas fluorescentes, para que após, possam ser encaminhados aos estabelecimentos obrigados ao sistema de logística reversa.

Quanto aos fármacos, embora exista Lei Federal (BRASIL, 1976) que regulamenta o descarte de medicamento pelas indústrias e farmácias, não há uma que trate do assunto em âmbito doméstico, assim, utilizando por analogia os instrumentos da logística reversa para os produtos elencados na PNRS (BRASIL, 2010), propõe-se que seja constituída parceria entre o Poder Público local e os estabelecimentos que fabricam, importam, distribuem e comercializam medicamentos como locais adequados para receberem estes produtos após seu uso pelo consumidor ou vencimento, proporcionando, assim, efetiva aplicação dos princípios do poluidor-pagador e responsabilidade compartilhada pelo ciclo de vida do produto. 
